\title{
UNDERSTANDING THE STRUCTURE, SUBSTITUENT EFFECT, NATURAL BOND ANALYSIS AND AROMATICITY OF OSMABENZYNE: A DFT STUDY
}

\author{
REZA GHIASI*a, HODA PASDAR ${ }^{b}$, FAROKH IRAJIZADEH ${ }^{b}$ \\ ${ }^{a}$ Department of Chemistry, Basic science faculty, East Tehran Branch, Islamic Azad University, Qiam Dasht, Tehran, IRAN. \\ ${ }^{b}$ Chemistry faculty, North Tehran Branch, Islamic Azad University, Tehran, IRAN.
}

\begin{abstract}
The structures and properties of osmabenzyne and para-substituted osmabenzynes $\left(\mathrm{X}=\mathrm{F}, \mathrm{Cl}, \mathrm{Br}, \mathrm{Me}, \mathrm{NH}_{2}, \mathrm{OH}, \mathrm{NO}, \mathrm{CHO}, \mathrm{COOH}\right)$ have been explored using theoretical methods. Frontier orbital analysis indicates the HOMO and LUMO are distributed on the ring carbon atoms, Os and $\mathrm{Cl}$ ligands. Time dependent density functional theory (TD-DFT) is used to calculate the energy, oscillatory strength and wavelength absorption maxima ( $\lambda_{\text {max }}$ ) of various electronic transitions and their nature within molecules. Non linear optical (NLO) behavior of title compounds is investigated by the computed value of first hyperpolarizability ( $\beta_{\text {total }}$ ).
\end{abstract}

\section{INTRODUCTION}

Metallabenzynes, ${ }^{1-6}$ which are organometallic compounds derived from formal replacement of a carbon atom or a C-H group in benzyne with an isolobal transition metal fragment, are closely related to metallabenzenes. At initial view, one might expect that metallabenzynes may be too unstable to be isolated, because organic compounds with a $\mathrm{C} \equiv \mathrm{C}$ bond in the six-membered ring, for example, benzyne and cyclohexyne, are thermally highly unstable because of ring strain. The first stable metallabenzyne $\left[\mathrm{Os}\left(\equiv \mathrm{CC}\left(\mathrm{SiMe}_{3}\right)=\mathrm{C}\left(\mathrm{CH}_{3}\right)\right.\right.$ $\mathrm{C}$ - $\left.\left(\mathrm{SiMe}_{3}\right)=\mathrm{CH}\right) \mathrm{Cl}_{2}\left(\mathrm{PPh}_{3}\right)_{2}$ ] was obtained unexpectly during effort to prepare osmium vinylidene complexes of the type $\left[\mathrm{OsCl}_{2}(=\mathrm{C}=\mathrm{CHR})\left(\mathrm{PR}_{3}\right)_{2}\right]^{7}$ However, in recent years, numerous stable osmabenzynes have been isolated ${ }^{8-12}$ and their interesting chemical properties have been determined. For instance, osmabenzynes, such as metallabenzenes and aromatic compounds, can undergo electrophilic substitution reactions ${ }^{9}$. Also, the electronic explanation for the stabilization of osmabenzyne has been studied with the aid of orbital interaction analysis and density functional theory calculations ${ }^{13}$.

In the present work, we have attempted to study the structure, molecular orbital analysis, reactivity, electronic spectra, hyperpolarizability, and natural bond orbital analysis in osmabenzyne and substituted osmabenzyne. These calculations are valuable for providing insight into structure and properties in osmabenzyne.

\section{COMPUTATIONAL METHODS}

All calculations were carried out with the Gaussian 03 suite of program ${ }^{14}$. The calculations of systems contain $\mathrm{C}, \mathrm{Br}, \mathrm{O}, \mathrm{N}, \mathrm{Cl}, \mathrm{P}, \mathrm{F}$ and $\mathrm{H}$ described by the standard 6-31G(d,p) basis set ${ }^{15-21}$. For Os element standard LANL2DZ basis set ${ }^{22-24}$ is used and Os described by effective core potential (ECP) of Wadt and Hay pseudopotential ${ }^{22}$ with a doublet- $\xi$ valence using the LANL2DZ. Geometry optimization was performed utilizing with Modified Perdew-Wang Exchange and Correlation (mpw1pw91) ${ }^{25}$. The results of calculations for transition metal complexes show that MPW1PW91 functional gives better results than B3LYP ${ }^{26-29}$. A vibrational analysis was performed at each stationary point found, that confirm its identity as an energy minimum.

Geometries were optimized at this level of theory without any symmetry constraints followed by the calculations of the first order hyperpolarizabilities. The total static first hyperpolarizability $\beta$ was obtained from the relation:

$$
\beta_{t o t}=\sqrt{\beta_{x}^{2}+\beta_{y}^{2}+\beta_{z}^{2}}
$$

upon calculating the individual static components

$$
\beta_{i}=\beta_{i i i}+\frac{1}{3} \sum_{i \neq j}\left(\beta_{i j j}+\beta_{j i j}+\beta_{j j i}\right)
$$

Due to the Kleinman symmetry ${ }^{30}$ :

$$
\beta_{x y y}=\beta_{y x y}=\beta_{y y x} ; \beta_{y y z}=\beta_{y z y}=\beta_{z y y} \cdots
$$

one finally obtains the equation that has been employed:

$\beta_{t o t}=\sqrt{\left(\beta_{x x x}+\beta_{x y y}+\beta_{x z z}\right)^{2}+\left(\beta_{y y y}+\beta_{y z z}+\beta_{y x x}\right)^{2}+\left(\beta_{z z z}+\beta_{z x x}+\beta_{z y y}\right)^{2}}$
The electronic spectra for the studied compounds were calculated by TD-DFT ${ }^{31}$ using the same hybrid functionals and basis sets as used for the calculation of the hyperpolarizabilities. The 10 lowest excitation energies were computed.

The population analysis has also been performed by the natural bond orbital method ${ }^{32}$ using NBO program ${ }^{33}$ under Gaussian 2003 program package.

GaussSum 2.2.6.1 was used to prepare total density of state (TDOS) or density of state ${ }^{34}$. The electron density difference map (EDDM) of the most intensity of the 10 lowest excitation were prepared from Gaussian03 TDDFT output using GaussSum and visualized using Gaussian viewer 5.0.

The nucleus-independent chemical shift (NICS) index, based on the magnetic criterion of aromaticity, is probably the most widely used probe for examination of chemical compounds aromatic properties ${ }^{35}$. It is defined as the negative value of the absolute magnetic shielding. It can be calculated in the centre of the aromatic ring $\left(\operatorname{NICS}(0)^{36}\right)$, or at $1 \AA$ above it $\left(\operatorname{NICS}(1)^{37}\right)$. Negative NICS values denote efficient electron delocalization. Nucleus-independent chemical shifts were calculated in the point located by $1 \AA$ above the center of the ring (NICS(1)zz) as it was recommended for obtaining more accurate data 38-39. NICS values are calculated using the Gauge independent atomic orbital (GIAO) ${ }^{40}$ method at the same method and basis sets for optimization.

\section{RESULTS AND DISCUSSION}

\section{Dipole moment}

The structures of osmabenzyne and para-substituted osmabenzynes and ring and ligands numbering are given in Figure. 1. The absolute energies and dipole moments values of these complexes are shown in Table 1. Studied complexes are in singlet spin state. It can be seen, the more dipole moments for electron donor substituents.

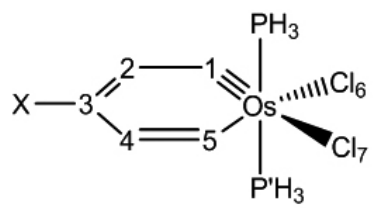

\section{Model complex}

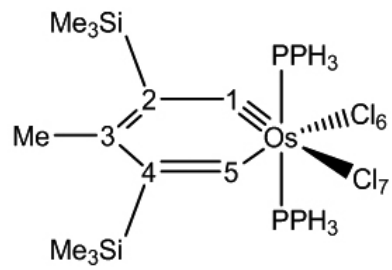

Synthesized complex

Figure 1. Structures of synthesized and model osmabenzyne. 
Table 1. Absolute energy (Hartree), dipole moment (Debye), maximum Absorption wavelength $\left(\lambda_{\max }, \mathrm{nm}\right)$, and Oscillator strength (f) for para-substituted $\mathrm{XC}_{5} \mathrm{H}_{3} \mathrm{Os}\left(\mathrm{PH}_{3}\right)_{2} \mathrm{Cl}_{2}$ complexes.

\begin{tabular}{|c|c|c|c|c|c|}
\hline $\mathbf{X}$ & $\mathbf{E}$ & $\mu_{\text {tot }}$ & $\lambda_{\max }$ & $\mathbf{f}$ & attributed \\
\hline $\mathbf{H}$ & -1890.733 & 6.53 & 287.50 & 0.0423 & HOMO-2 $\rightarrow$ LUMO+1 \\
\hline $\mathbf{F}$ & -1989.947 & 5.24 & 284.21 & 0.0409 & HOMO-4 $\rightarrow$ LUMO \\
\hline $\mathbf{C l}$ & -2350.336 & 4.81 & 294.09 & 0.0483 & HOMO-4 $\rightarrow$ LUMO \\
\hline $\mathbf{B r}$ & -4461.697 & 4.94 & 296.83 & 0.0514 & HOMO-4 $\rightarrow$ LUMO \\
\hline $\mathbf{M e}$ & -1930.048 & 7.51 & 286.45 & 0.0438 & HOMO-2 $\rightarrow$ LUMO+1 \\
\hline $\mathbf{O H}$ & -1965.945 & 7.80 & 306.55 & 0.0389 & HOMO-1 $\rightarrow$ LUMO+1 \\
\hline $\mathbf{N H}$ & -1946.096 & 10.57 & 300.39 & 0.0713 & HOMO-1 $\rightarrow$ LUMO+1 \\
\hline $\mathbf{C N}$ & -1982.942 & 1.58 & 333.54 & 0.0235 & HOMO-3 $\rightarrow$ LUMO \\
\hline $\mathbf{C H O}$ & -2004.023 & 3.96 & 347.26 & 0.0255 & HOMO-4 $\rightarrow$ LUMO \\
\hline $\mathbf{C O O H}$ & -2079.258 & 5.44 & 336.83 & 0.0239 & HOMO-4 $\rightarrow$ LUMO \\
\hline $\mathbf{N O}$ & -2095.174 & 1.39 & 352.08 & 0.0218 & HOMO-3 $\rightarrow$ LUMO \\
\hline
\end{tabular}

\section{Molecular geometries}

Selected interatomic distances for osmabenzyne and para-substituted osmabenzyne have been tabulated in Table 2 in order to compare the effect of para substituent on the molecular skeleton of osmabenzyne.

\section{Os-C bonds:}

These values show that Os- $\mathrm{C} 1$ and $\mathrm{Os}-\mathrm{C} 5$ bonds are longer in electron donor substituents. For analyzing of these bonds, the model complexes $\left[\mathrm{OsCl}_{2}\left(\mathrm{CH}_{3}\right)\right.$ $\left.\left(=\mathrm{CH}_{2}\right)\left(\mathrm{PH}_{3}\right)_{2}\right]$ and $\mathrm{OsCl}_{2}\left(\mathrm{CH}_{3}\right)(\equiv \mathrm{CH})\left(\mathrm{PH}_{3}\right)_{2}$ optimized MPW1PW91 method and the same basis sets used for studied osmabenzynes. The Os-C5 bond length is slightly shorter than that for calculated Os-C single bond $(2.149 \AA)$, and longer than that for calculated Os-C double bond (1.870 $\AA$ ). The bond distance of Os-C1 is intermediate between normal Os-C double and triple bonds, $(1.870$, $1.719 \AA$ respectively). The bond distance data demonstrate the delocalization of bonding, a typical character of aromatic property.

Os-Cl bonds:

On the other hand, Os-Cl7 bond lengths decrease in the presence of electron donor substituents. Os-Cl6 bond distances decreases in the presence of all substituents. Also, Os-Cl7 bond are longer than Os-Cl6 bonds in all complexes.

\section{CC bonds:}

The analysis of $\mathrm{CC}$ bond lengths reveals these bonds are intermediate between normal single and double bonds, $\left(1.327,1.523 \AA\right.$ in $\mathrm{C}_{2} \mathrm{H}_{4}$ and $\mathrm{C}_{2} \mathrm{H}_{6}$ respectively, by MPW1PW91 method and using the 6-31g(d,p) basis set). The bond distance data demonstrate the delocalization of bonding, a typical character of aromatic property.

\section{$P$-Os-P bond angles}

P-Os-P bond angles values are gathered in Table 2. These values increase in the presence of electron donor substituents. The bending of P-Os-P is expected to enhance the $\mathrm{dxz}-3 \pi$ back-bonding interaction between the metal and carbon unit; as a result helps the aromaticity of the metallacycle ${ }^{13}$.

Although theoretical results are not exactly close to the experimental values ${ }^{8}$ for the title molecule, this may due to the fact that the theoretical calculations were aimed at the isolated molecule in gaseous phase and the experimental results were aimed at the molecule in the solid state, the calculated geometric parameters also represents good approximation and they can be used as foundation to calculate the other parameters for the compound.

Table $2 \mathrm{O}_{\mathrm{s}}-\mathrm{C}_{1}, \mathrm{C}-\mathrm{C}, \mathrm{O}_{\mathrm{s}}-\mathrm{Cl}$ Bond distances and $\mathrm{P}-\mathrm{O}_{\mathrm{s}}-\mathrm{P}$ bond angle values for para-substituted $\mathrm{XC}_{5} \mathrm{H}_{3} \mathrm{Os}\left(\mathrm{PH}_{3}\right)_{2} \mathrm{Cl}_{2}$ complexes.

\begin{tabular}{|c|c|c|c|c|c|c|c|c|c|}
\hline $\mathbf{X}$ & $\mathbf{O s - C 1}$ & $\mathbf{C 1 - C 2}$ & $\mathbf{C 2 - C 3}$ & $\mathbf{C 3 - C 4}$ & $\mathbf{C 4 - C 5}$ & $\mathbf{C 5 - O s}$ & Os-C16 & Os-C17 & $\angle \mathbf{P}-\mathbf{O s - P}$ \\
\hline $\mathbf{H}$ & 1.773 & 1.371 & 1.396 & 1.410 & 1.384 & 2.018 & 2.483 & 2.497 & 160.84 \\
\hline $\mathbf{E x p}$ & 1.815 & 1.376 & 1.420 & 1.416 & 1.378 & 1.939 & 2.481 & 2.480 & 171.00 \\
\hline $\mathbf{F}$ & 1.774 & 1.369 & 1.392 & 1.410 & 1.377 & 2.028 & 2.475 & 2.490 & 161.71 \\
\hline $\mathbf{C l}$ & 1.773 & 1.370 & 1.395 & 1.414 & 1.380 & 2.022 & 2.476 & 2.491 & 161.19 \\
\hline $\mathbf{B r}$ & 1.773 & 1.370 & 1.395 & 1.413 & 1.381 & 2.021 & 2.476 & 2.491 & 161.17 \\
\hline $\mathbf{M e}$ & 1.772 & 1.370 & 1.400 & 1.421 & 1.379 & 2.023 & 2.483 & 2.498 & 161.46 \\
\hline $\mathbf{N H}$ & 1.781 & 1.359 & 1.415 & 1.434 & 1.369 & 2.036 & 2.478 & 2.495 & 163.86 \\
\hline $\mathbf{O H}$ & 1.776 & 1.365 & 1.405 & 1.421 & 1.372 & 2.034 & 2.476 & 2.492 & 162.72 \\
\hline $\mathbf{C N}$ & 1.772 & 1.370 & 1.403 & 1.417 & 1.384 & 2.014 & 2.476 & 2.491 & 159.83 \\
\hline $\mathbf{C H O}$ & 1.776 & 1.366 & 1.400 & 1.410 & 1.388 & 2.009 & 2.482 & 2.495 & 159.75 \\
\hline $\mathbf{C O O H}$ & 1.773 & 1.368 & 1.399 & 1.412 & 1.386 & 2.013 & 2.481 & 2.494 & 160.25 \\
\hline $\mathbf{N O}$ & 1.772 & 1.371 & 1.390 & 1.403 & 1.386 & 2.013 & 2.476 & 2.489 & 159.66 \\
\hline
\end{tabular}

* See Figure 1; X=Me: T.B. Wen, Z.Y. Zhou, G. Jia, Angew. Chem. Int. Ed. Engl. 40 (2001) 1951.

\section{Polarizability}

Polarizabilities describe the response of a system in an applied electric field. They determine not only the strength of molecular interactions (such as the long range intermolecular induction, dispersion forces, etc.) as well as the cross sections of different scattering and collision processes, but also the nonlinear optical properties of the system ${ }^{41}$. 
The isotropic polarizability $<\alpha>$ is calculated as the mean value as given in the following equation ${ }^{42}$ :

$$
\begin{gathered}
<\alpha>=\frac{\alpha_{x x}+\alpha_{y y}+\alpha_{z z}}{3} \\
\text { And anisotropic polarizability with: } \\
\Delta \alpha=\left[\frac{\left(\alpha_{X X}-\alpha_{Y Y}\right)^{2}+\left(\alpha_{Y Y}-\alpha_{Z Z}\right)^{2}+\left(\alpha_{Z Z}-\alpha_{X X}\right)^{2}}{2}\right]^{\frac{1}{2}}
\end{gathered}
$$

The calculated isotropic and anisotropic polarizability values indicate these values increase in all complexes (Table 3). Also, these values reveal electron withdrawing substituents have more isotropic and anisotropic polarizability values rather than electron donor substituents.

Table 3. Isotropic and anisotropic polarizability values for para-substituted $\mathrm{XC}_{5} \mathrm{H}_{3} \mathrm{Os}\left(\mathrm{PH}_{3}\right)_{2} \mathrm{Cl}_{2}$ complexes.

\begin{tabular}{|c|c|c|c|c|c|}
\hline $\mathbf{X}$ & $\alpha \mathbf{x x}$ & $\alpha \mathbf{y y}$ & $\alpha \mathbf{z z}$ & $\langle\alpha\rangle$ & $\Delta \alpha$ \\
\hline $\mathbf{H}$ & 195.00 & 143.97 & 142.05 & 160.34 & 52.02 \\
\hline $\mathbf{F}$ & 198.41 & 144.57 & 140.87 & 161.28 & 55.78 \\
\hline $\mathbf{C l}$ & 239.64 & 147.61 & 144.96 & 177.40 & 93.38 \\
\hline $\mathbf{B r}$ & 258.71 & 151.07 & 147.95 & 185.91 & 109.23 \\
\hline $\mathbf{M e}$ & 225.89 & 152.71 & 148.52 & 175.71 & 75.36 \\
\hline $\mathbf{O H}$ & 213.13 & 146.05 & 142.47 & 167.22 & 68.93 \\
\hline $\mathbf{N H}_{2}$ & 231.28 & 147.65 & 143.90 & 174.28 & 85.57 \\
\hline $\mathbf{C N}$ & 255.47 & 148.09 & 146.68 & 183.41 & 108.09 \\
\hline $\mathbf{N O}$ & 236.68 & 148.51 & 155.85 & 180.34 & 84.74 \\
\hline $\mathbf{C O O H}$ & 243.15 & 150.38 & 154.20 & 182.58 & 90.92 \\
\hline $\mathbf{C H O}$ & 242.21 & 148.39 & 152.41 & 181.00 & 91.88 \\
\hline
\end{tabular}

4. Molecular orbital analysis

The energies of the frontier orbitals (HOMO, LUMO) along with the corresponding HOMO-LUMO energy gaps, Hardness, chemical potential, and electrophilicity for para-substituted $\mathrm{XC}_{5} \mathrm{H}_{3} \mathrm{Os}\left(\mathrm{PH}_{3}\right)_{2} \mathrm{Cl}_{2}$ complexes are gathered in Table 4. Frontier orbital analysis presents the HOMO and LUMO are distributed on the $\mathrm{Os}, \mathrm{Cl}$ and ring. The $\mathrm{HOMO}$ of $\mathrm{C}_{5} \mathrm{H}_{4} \mathrm{Os}\left(\mathrm{PH}_{3}\right)_{2} \mathrm{Cl}_{2}$ is at -0.2317 Hartree while its LUMO is at -0.09116 Hartree as calculated. This yields an $\mathrm{HOMO}-\mathrm{LUMO}$ energy gap of $3.82 \mathrm{eV}$. These energies represent reference values to compare against those calculated for derivatives bearing the chemical groups.

Table 4. Frontier orbital energies (Hartree), $\mathrm{HOMO}-\mathrm{LUMO}$ gap energy (eV), hardness (eV), and chemical potential $(\mathrm{eV})$ for para-substituted XC $\mathrm{H}_{3} \mathrm{Os}_{2}\left(\mathrm{PH}_{3}\right)_{2} \mathrm{Cl}_{2}$ complexes.

\begin{tabular}{|c|c|c|c|c|c|c|}
\hline $\mathbf{X}$ & $\mathbf{E}(\mathbf{H O M O})$ & $\mathbf{E}(\mathbf{L U M O})$ & $\Delta \mathbf{E}$ & $\eta$ & $\mu$ & $\omega$ \\
\hline $\mathbf{H}$ & -0.2317 & -0.0912 & 3.83 & 1.91 & -4.39 & 5.05 \\
\hline $\mathbf{F}$ & -0.2384 & -0.0895 & 4.05 & 2.03 & -4.46 & 4.91 \\
\hline $\mathbf{C l}$ & -0.2397 & -0.0987 & 3.84 & 1.92 & -4.60 & 5.52 \\
\hline $\mathbf{B r}$ & -0.2394 & -0.0994 & 3.81 & 1.91 & -4.61 & 5.58 \\
\hline $\mathbf{M e}$ & -0.2286 & -0.0854 & 3.90 & 1.95 & -4.27 & 4.69 \\
\hline $\mathbf{O H}$ & -0.2305 & -0.0766 & 4.19 & 2.09 & -4.18 & 4.17 \\
\hline $\mathbf{N H}$ & -0.2216 & -0.0626 & 4.33 & 2.16 & -3.87 & 3.45 \\
\hline $\mathbf{C N}$ & -0.2484 & -0.1231 & 3.41 & 1.71 & -5.05 & 7.49 \\
\hline $\mathbf{C O O H}$ & -0.2376 & -0.1145 & 3.35 & 1.68 & -4.79 & 6.85 \\
\hline $\mathbf{C H O}$ & -0.2410 & -0.1231 & 3.21 & 1.60 & -4.95 & 7.65 \\
\hline $\mathbf{N O}$ & -0.2500 & -0.1336 & 3.17 & 1.58 & -5.22 & 8.60 \\
\hline
\end{tabular}

The replacement of para hydrogen atom of osmabenzyne by different groups has the effect to frontier orbital energies. In the presence of electron withdrawing and halogens substituents, HOMO energies decrease. On the other hand, electron withdrawing substituents decrease LUMO energies. Also, donor groups have the effect to increasing hardness and chemical potential, while $\omega$ (electrophilicity index) parameters are decreasing in the reverse order.

Also, The atomic orbital compositions and the density of states (DOS) of the frontier molecular orbital of $\mathrm{C}_{5} \mathrm{H}_{4} \mathrm{Os}\left(\mathrm{PH}_{3}\right)_{2} \mathrm{Cl}_{2}$ are sketched in Figure 2. This figure presents frontier orbitals involve $\pi$-bonding overlap between carbon atoms.

\section{Aromaticity}

Table 5 encloses the values corresponding to NICS aromaticity criteria ${ }^{35}$. NICS values have been calculated in center and $0.5,1.0,1.5$, and $2.0 \AA$ above of the center of rings. In $\mathrm{X}=\mathrm{Br}, \mathrm{CN}, \mathrm{CHO}$ substituents, the most negative NICS values are $0.5 \AA$ above of the rings center. This is compatible with $\pi$-aromaticity in these rings. In other substituents, the most negative NICS values are in the center of rings center for all species that reveals $\sigma$-aromaticity in these rings. Also, the NICS values exhibit increasing of aromaticity in electron withdrawing substituents. In addition, we focused on the NICS(1) index to elucidate the variation of the degree of aromaticity in all ring. Again, there is more aromaticity for electron withdrawing substituents.

6. Electronic spectra

We found the most intensity electronic transition $\left(\lambda_{\max }\right)$ of all complexes. The wavelength, oscillator strength and the composition of the transitions obtained by TD-DFT calculations are given in Table 1 .

The energies of the most intensity transition $\left(\lambda_{\max }\right)$ show that the acceptor 
derivatives are strongly affected by the accepting strength of the X-group. On the other hand, for the donor derivatives, this value is only slightly affected by the X-group.

Although the electronic structures of the excited states are not available using TDDFT approach, the electron distribution and so the amount of localization of the excited state may be visualized readily using electron density difference maps (EDDMs), as shown in Figure 4 for $\mathrm{C}_{5} \mathrm{H}_{4} \mathrm{Os}\left(\mathrm{PH}_{3}\right)_{2} \mathrm{Cl}_{2}$. The EDDM for the lowest energy transition of $\mathrm{C}_{5} \mathrm{H}_{4} \mathrm{Os}\left(\mathrm{PH}_{3}\right)_{2} \mathrm{Cl}_{2}$ shows a decrease in charge density at the $\mathrm{Cl} 7$ and a corresponding increase on metal centre, $\mathrm{C} 5$, hence, the most intensity transition is LMCT.

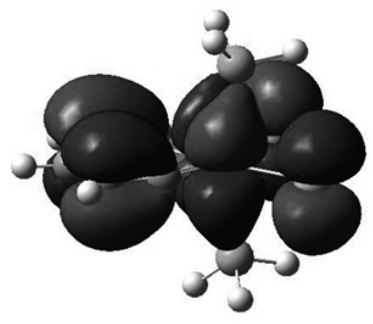

номо

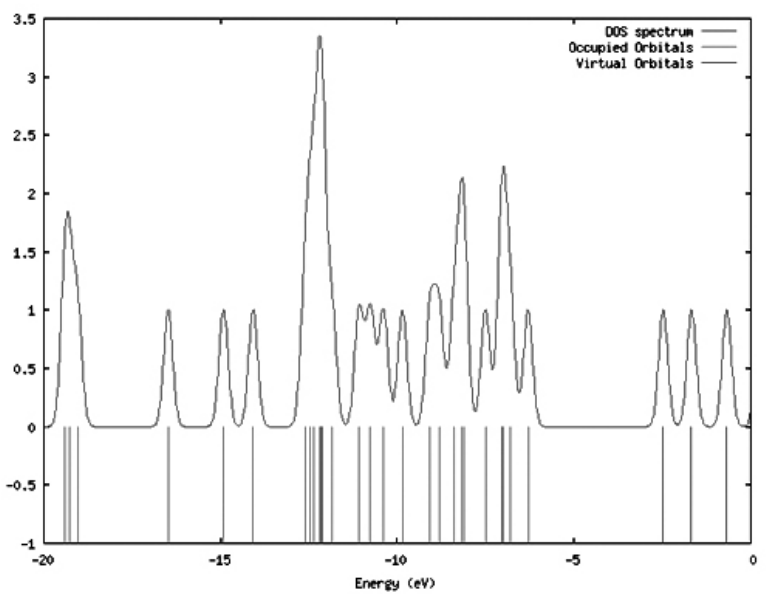

Figure 2. Plots and density of states (DOS) of Frontier orbitals for $\mathrm{C}_{5} \mathrm{H}_{3} \mathrm{Os}\left(\mathrm{PH}_{3}\right)_{2} \mathrm{Cl}_{2}$ complex.

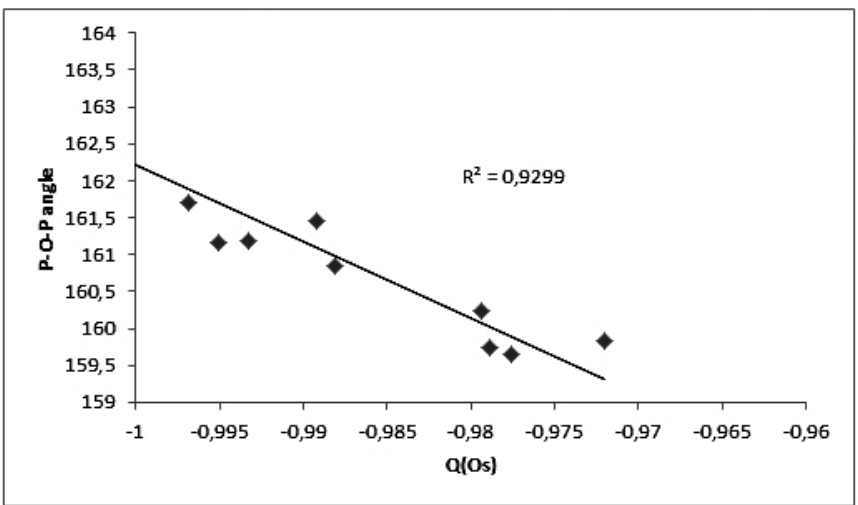

Figure 3. Linear correlation between $\angle \mathrm{P}-\mathrm{O}-\mathrm{P}$ with charge of Os atom.

\section{Hyperpolarizability}

Theoretical investigation cooperate an essential role in comprehending the structure-property correlation, which is able to support in designing novel NLO chromophores. The electrostatic first hyperpolarizability $\left(\beta_{\text {tot }}\right)$ and dipole moment $(\mu)$ of para-substituted $\mathrm{XC}_{5} \mathrm{H}_{4} \mathrm{Os}\left(\mathrm{PH}_{3}\right)_{2} \mathrm{Cl}$ complexes have been calculated. From Table 6 , it is found that when $\mathrm{X}=\mathrm{NO}_{2}$ show larger $\mu \beta$ values, which is attributed to the positive contribution of their conjugation. Also, $\beta_{\text {tot }}$ values increase in the presence of electron withdrawing.

\section{Natural bond analysis (NBO)}

\section{Charge distribution}

Table 8 presents the atomic charges of Os and ligands atoms from the natural population analysis (NPA) for studied complexes. The calculated charges on the osmium atoms are considerable lower than the formal charge +2 . This is a result of significant charge donation from $\mathrm{PH}_{3}, \mathrm{Cl}$, ligands and ring carbon atoms. Figure 3 indicates a good correlation between $\angle \mathrm{P}-\mathrm{O}-\mathrm{P}$ angle and charge of Os. $\angle \mathrm{P}-\mathrm{O}-\mathrm{P}$ angle increase, when there is more negative charge on Os.

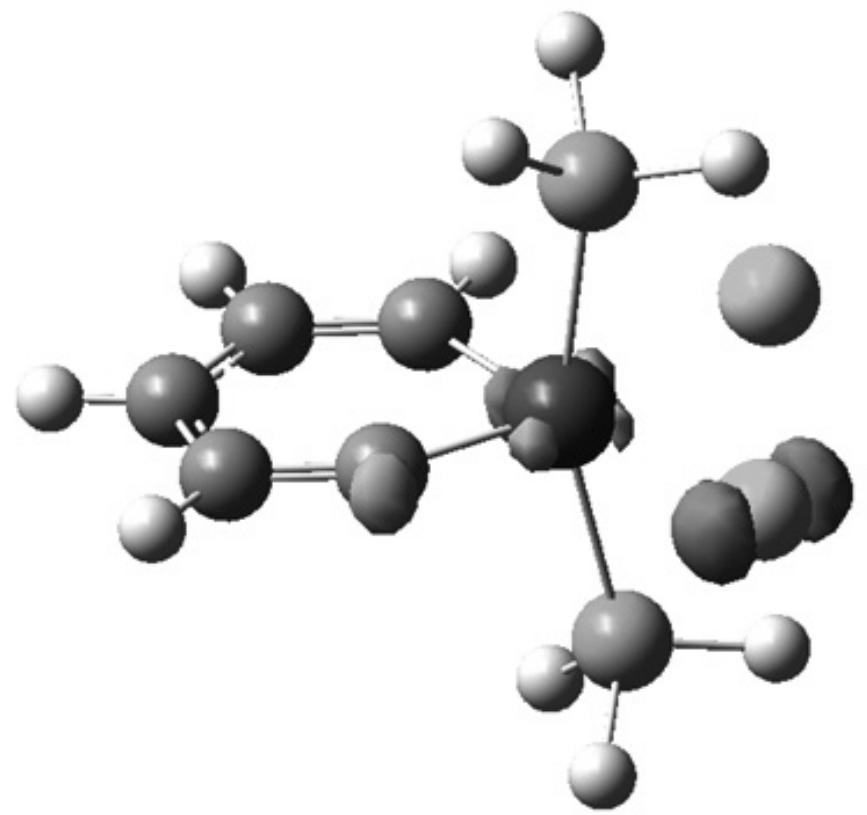

Figure 4. Electron density difference maps (EDDMs) of the most intensity singlet electronic transition of $\mathrm{C}_{5} \mathrm{H}_{4} \mathrm{Os}\left(\mathrm{PH}_{3}\right)_{2} \mathrm{Cl}_{2}$. The blue represents where the electrons are coming from, and the purple represents where the electrons are going.

\section{Wiberg indices}

The bond delocalization can also be found from the calculated bond indice. The bond delocalization can also be found the calculated bond indices are comparable to the calculated those for benzene (1.438). The Os-C5 bond indices are intermediate between calculated OsC single and double bond indices ( 0.617 and 1.463 , respectively). OsC1 bond indices are within the range of those for OsC double and triple bonds (1.463 and 2.046, respectively).

\section{Character of natural hybrid orbital (NHO) on the complexes}

In Table 9, we present the resulted natural atomic hybrids hA on Os and carbon atoms with the polarization coefficient for Os-C1 and Os-C2 hybrid in the corresponding NBO. The inspection of the results reported in Table 9 reveals that:

1. The $\mathrm{p}$ characters of carbon $\mathrm{NHO} \sigma(\mathrm{Os}-\mathrm{C} 5)$ decrease in substituted species.

2. The $\mathrm{p}$ and $\mathrm{d}$ characters of osmium $\mathrm{NHO} \sigma(\mathrm{Os}-\mathrm{C} 5)$ decrease in electron withdrawing substituted species, and increase in electron donor substituted species.

3. The $\mathrm{p}$ characters of carbon and osmium $\mathrm{NHO} \sigma(\mathrm{Os}-\mathrm{C} 5)$ are more than $\mathrm{NHO} \sigma(\mathrm{Os}-\mathrm{C} 1)$ decrease in substituted species. This results in a lengthening of the OsC5 bond. 
J. Chil. Chem. Soc., 60, № 4 (2015)

Table 5. The NICS(0.0), NICS(0.5), NICS(1.0), NICS(1.5), and NICS(2.0) (ppm) values for para-substituted $\mathrm{XC}_{5} \mathrm{H}_{3} \mathrm{Os}_{2}\left(\mathrm{PH}_{3}\right)_{2} \mathrm{Cl}_{2}$ complexes.

\begin{tabular}{|c|c|c|c|c|c|c|c|c|c|c|}
\hline $\mathbf{X}$ & $\mathbf{N I C S}(\mathbf{0 . 0})$ & $\mathbf{N I C S}(\mathbf{0 . 5})$ & $\mathbf{N I C S}(\mathbf{1 . 0})$ & $\mathbf{N I C S}(\mathbf{1 . 5})$ & $\mathbf{N I C S}(\mathbf{2 . 0})$ & $\begin{array}{c}\mathbf{N I C S}(\mathbf{0 . 0}) \\
\mathbf{z z}\end{array}$ & $\begin{array}{c}\mathbf{N I C S}(\mathbf{0 . 5}) \\
\mathbf{z z}\end{array}$ & $\begin{array}{c}\mathbf{N I C S}(\mathbf{1 . 0}) \\
\mathbf{z z}\end{array}$ & $\begin{array}{c}\mathbf{N I C S}(\mathbf{1 . 5}) \\
\mathbf{z z}\end{array}$ & $\begin{array}{c}\mathbf{N I C S}(\mathbf{2 . 0}) \\
\mathbf{z z}\end{array}$ \\
\hline $\mathbf{H}$ & -7.48 & -7.41 & -6.51 & -4.91 & -3.44 & -7.18 & -8.89 & -12.11 & -11.56 & -8.73 \\
\hline $\mathbf{F}$ & -8.04 & -7.38 & -5.99 & -4.28 & -2.87 & -4.53 & -7.56 & -11.10 & -10.75 & -8.13 \\
\hline $\mathbf{C l}$ & -8.96 & -8.63 & -7.34 & -5.32 & -3.55 & -6.81 & -9.37 & -12.83 & -12.32 & -9.36 \\
\hline $\mathbf{B r}$ & -7.50 & -8.16 & -7.24 & -5.01 & -3.20 & -4.00 & -9.41 & -13.84 & -12.26 & -8.74 \\
\hline $\mathbf{M e}$ & -7.96 & -7.64 & -6.51 & -4.75 & -3.21 & -6.34 & -9.61 & -12.73 & -11.84 & -8.84 \\
\hline $\mathbf{O H}$ & -6.53 & -6.19 & -5.16 & -3.73 & -2.53 & -0.40 & -4.33 & -9.24 & -9.67 & -7.52 \\
\hline $\mathbf{N H}$ & -7.92 & -6.89 & -5.09 & -3.50 & -2.37 & -1.34 & -4.36 & -8.20 & -8.69 & -6.81 \\
\hline $\mathbf{C N}$ & -8.18 & -8.29 & -7.42 & -5.45 & -3.64 & -7.42 & -11.47 & -15.06 & -13.58 & -9.94 \\
\hline $\mathbf{C H O}$ & -6.54 & -7.57 & -7.26 & -5.32 & -3.52 & -4.02 & -10.78 & -15.63 & -13.68 & -9.71 \\
\hline $\mathbf{C O O H}$ & -8.93 & -8.93 & -7.83 & -5.67 & -3.75 & -8.06 & -12.26 & -15.15 & -13.23 & -9.48 \\
\hline $\mathbf{N O}$ & -9.44 & -9.17 & -7.80 & -5.59 & -3.70 & -8.63 & -12.41 & -14.91 & -13.09 & -9.47 \\
\hline
\end{tabular}

Table 6. $\beta$ components and $\beta_{\text {tot }}$ values $\left(10^{-30} \mathrm{esu}\right)$ for para-substituted $\mathrm{XC}_{5} \mathrm{H}_{3} \mathrm{Os}\left(\mathrm{PH}_{3}\right)_{2} \mathrm{Cl}_{2}$ complexes.

\begin{tabular}{|c|c|c|c|c|c|c|c|c|c|c|c|}
\hline $\mathrm{X}$ & $\mathbf{H}$ & $\mathbf{F}$ & Cl & $\mathrm{Br}$ & Me & OH & $\mathbf{N H}_{2}$ & $\mathrm{NO}_{2}$ & CHO & $\mathrm{COOH}$ & $\mathrm{CN}$ \\
\hline$\beta_{\mathrm{xxx}}$ & -514.63 & -254.61 & -37.34 & 53.87 & -275.43 & -180.64 & -108.56 & -991.86 & -855.52 & -844.62 & -380.40 \\
\hline$\beta_{\mathrm{XXY}}$ & -13.11 & -14.45 & 3.33 & 10.78 & -11.42 & 12.36 & -56.45 & -56.75 & -84.56 & -92.28 & -53.26 \\
\hline$\beta_{\mathrm{XYY}}$ & -308.18 & -313.81 & -319.51 & -319.61 & -332.28 & -333.35 & -355.21 & -284.61 & -338.21 & -283.82 & -334.99 \\
\hline$\beta_{\mathrm{YYY}}$ & 36.37 & 35.89 & 38.16 & 36.85 & 55.35 & 30.36 & 72.35 & 72.51 & 28.26 & 66.39 & 44.57 \\
\hline $\boldsymbol{\beta}_{\mathrm{xxz}}$ & -1.85 & -3.77 & -7.51 & -6.90 & -5.69 & -10.91 & -5.61 & -8.33 & -8.36 & -7.45 & -4.63 \\
\hline$\beta_{\mathrm{XYZ}}$ & 7.24 & 5.14 & 6.03 & 5.43 & 9.41 & 8.32 & -5.61 & -8.96 & 3.76 & 3.52 & 4.59 \\
\hline $\boldsymbol{\beta}_{\mathrm{YYZ}}$ & -1.19 & -0.03 & -0.15 & -0.84 & -5.41 & -8.85 & 0.23 & -1.40 & -1.62 & -0.08 & -2.14 \\
\hline $\boldsymbol{\beta}_{\mathrm{xzz}}$ & 8.18 & 18.70 & 36.57 & 41.06 & 7.72 & 42.70 & 75.69 & 4.84 & 18.31 & 18.56 & 23.24 \\
\hline $\boldsymbol{\beta}_{\mathrm{yzz}}$ & 17.23 & 16.64 & 16.63 & 16.14 & 1.64 & 18.47 & 19.04 & 11.90 & 10.79 & 13.00 & 13.75 \\
\hline $\boldsymbol{\beta}_{\mathrm{zzz}}$ & -7.43 & -6.18 & -5.30 & -5.63 & 1.04 & -2.48 & -4.60 & -4.76 & -5.21 & -6.66 & -4.43 \\
\hline $\boldsymbol{\beta}_{\text {tot }}$ & $7.05 \mathrm{E}-30$ & $4.76 \mathrm{E}-30$ & $2.81 \mathrm{E}-30$ & $2.02 \mathrm{E}-30$ & $5.20 \mathrm{E}-30$ & $4.11 \mathrm{E}-30$ & $3.37 \mathrm{E}-30$ & $1.1 \mathrm{E}-29$ & $1.02 \mathrm{E}-29$ & $9.59 \mathrm{E}-30$ & $5.98 \mathrm{E}-30$ \\
\hline$\beta_{\text {tot }} \times 10^{-30}$ & 7.05 & 4.76 & 2.81 & 2.02 & 5.20 & 4.11 & 3.37 & 10.99 & 10.16 & 9.59 & 5.98 \\
\hline
\end{tabular}

Table 7. Calculated Wiberg bond indices (from NBO) in para-substituted $\mathrm{XC}_{5} \mathrm{H}_{3} \mathrm{Os}\left(\mathrm{PH}_{3}\right)_{2} \mathrm{Cl}_{2}$ complexes.

\begin{tabular}{|c|c|c|c|c|c|c|c|}
\hline $\mathbf{X}$ & $\mathbf{O s - C 1}$ & $\mathbf{C 1 - C 2}$ & $\mathbf{C 2 - C 3}$ & $\mathbf{C 3 - C 4}$ & $\mathbf{C 4 - C 5}$ & $\mathbf{C 5 - O s}$ & sum \\
\hline $\mathbf{H}$ & 1.8749 & 1.4103 & 1.4204 & 1.3446 & 1.5471 & 0.9887 & 8.586 \\
\hline $\mathbf{F}$ & 1.8711 & 1.4205 & 1.3716 & 1.2904 & 1.5742 & 0.9650 & 8.4928 \\
\hline $\mathbf{C l}$ & 1.8718 & 1.4066 & 1.3835 & 1.3004 & 1.5561 & 0.9747 & 8.4931 \\
\hline $\mathbf{B r}$ & 1.8695 & 1.4057 & 1.3896 & 1.3090 & 1.5523 & 0.9745 & 8.5006 \\
\hline $\mathbf{M e}$ & 1.8741 & 1.4128 & 1.3935 & 1.2885 & 1.5845 & 0.9654 & 8.5188 \\
\hline $\mathbf{N H}$ & 1.8223 & 1.4922 & 1.2744 & 1.2035 & 1.6507 & 0.9234 & 8.3665 \\
\hline $\mathbf{O H}$ & 1.8582 & 1.4443 & 1.3290 & 1.2438 & 1.6168 & 0.9400 & 8.4321 \\
\hline $\mathbf{C N}$ & 1.8850 & 1.4040 & 1.3584 & 1.2893 & 1.5362 & 0.9978 & 8.4707 \\
\hline $\mathbf{C H O}$ & 1.8534 & 1.4273 & 1.3542 & 1.3183 & 1.5151 & 1.0157 & 8.484 \\
\hline $\mathbf{C O O H}$ & 1.8684 & 1.4139 & 1.3712 & 1.3156 & 1.5269 & 1.0042 & 8.5002 \\
\hline $\mathbf{N O}$ & 1.8849 & 1.3900 & 1.3886 & 1.3251 & 1.5142 & 1.0070 & 8.5098 \\
\hline
\end{tabular}


Table 8. Calculated atomic charge by NBO analysis of selected atoms in para-substituted $\mathrm{XC}_{5} \mathrm{H}_{3} \mathrm{Os}_{(}\left(\mathrm{PH}_{3}\right)_{2} \mathrm{Cl}_{2}$ complexes.

\begin{tabular}{|c|c|c|c|c|c|c|c|}
\hline $\mathbf{X}$ & $\mathbf{Q}(\mathbf{O s})$ & $\mathbf{Q}(\mathbf{P})$ & $\mathbf{Q}\left(\mathbf{P}^{\prime}\right)$ & $\mathbf{Q}(\mathbf{C l 6})$ & $\mathbf{Q}(\mathbf{C l 7})$ & $\mathbf{Q}(\mathbf{C 1})$ & $\mathbf{Q}(\mathbf{C 5})$ \\
\hline $\mathbf{H}$ & -0.98812 & 0.50386 & 0.50623 & -0.35691 & -0.37234 & 0.34494 & -0.15086 \\
\hline $\mathbf{F}$ & -0.99685 & 0.50250 & 0.50448 & -0.34573 & -0.36146 & 0.33567 & -0.15092 \\
\hline $\mathbf{C l}$ & -0.99331 & 0.50294 & 0.50508 & -0.34704 & -0.36186 & 0.34331 & -0.14909 \\
\hline $\mathbf{B r}$ & -0.99508 & 0.50442 & 0.50603 & -0.34773 & -0.36178 & 0.33835 & -0.14545 \\
\hline $\mathbf{M e}$ & -0.98915 & 0.50286 & 0.50617 & -0.35817 & -0.37171 & 0.35049 & -0.15954 \\
\hline $\mathbf{N H}$ & -1.01318 & 0.50375 & 0.50637 & -0.35999 & -0.37589 & 0.32934 & -0.16739 \\
\hline $\mathbf{O H}$ & -1.00165 & 0.50293 & 0.50544 & -0.35379 & -0.36725 & 0.33315 & -0.15655 \\
\hline $\mathbf{C N}$ & -0.97201 & 0.50327 & 0.50448 & -0.34242 & -0.35849 & 0.33608 & -0.15214 \\
\hline $\mathbf{C H O}$ & -0.97885 & 0.50447 & 0.50608 & -0.35153 & -0.36716 & 0.34436 & -0.14641 \\
\hline $\mathbf{C O O H}$ & -0.97934 & 0.50372 & 0.50617 & -0.35152 & -0.36601 & 0.34040 & -0.14714 \\
\hline $\mathbf{N O}$ & -0.97754 & 0.50356 & 0.50503 & -0.34155 & -0.35502 & 0.34529 & -0.14530 \\
\hline
\end{tabular}

Table 9. Calculated natural hybrid (NHOs), occupancy and the polarization coefficient for each hybrid in the corresponding NBO for para-substituted $\mathrm{XC}_{5} \mathrm{H}_{3} \mathrm{Os}\left(\mathrm{PH}_{3}\right)_{2} \mathrm{Cl}_{2}$ complexes.

Os-C1 bond:

\begin{tabular}{|c|c|c|}
\hline $\mathbf{X}$ & occupancy & NBO \\
\hline $\mathbf{H}$ & $\begin{array}{l}1.85553 \\
1.87950 \\
1.78479\end{array}$ & $\begin{array}{c}\sigma: 0.7863 \mathrm{C} \text { sp } 0.85+0.6179 \text { Os sp } 1.69 \mathrm{~d} 1.95 \\
\pi: 0.5785 \mathrm{C} \text { sp87.24d } 0.10+0.8157 \text { Os p } 1.00 \mathrm{~d} 6.61 \\
\pi: 0.5119 \mathrm{C} \text { sp } 1.00+0.8590 \text { Os p } 1.00 \mathrm{~d} 6.84\end{array}$ \\
\hline $\mathbf{F}$ & $\begin{array}{l}1.85664 \\
1.87407 \\
1.79884\end{array}$ & 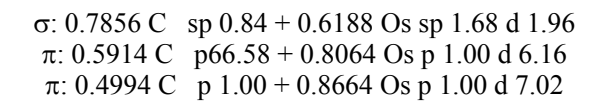 \\
\hline $\mathrm{Cl}$ & $\begin{array}{l}1.85400 \\
1.86986 \\
1.78957\end{array}$ & $\begin{array}{c}\sigma: 0.7831 \mathrm{C} \text { sp } 0.86+0.6219 \text { Os sp } 1.65 \mathrm{~d} 1.98 \\
\pi: 0.5907 \mathrm{C} \text { p53.56 + } 0.8069 \text { Os p99.99 d99.99 } \\
\pi: 0.5065 \mathrm{C} \text { p } 1.00+0.8622 \text { Os p } 1.00 \mathrm{~d} 6.94\end{array}$ \\
\hline $\mathrm{Br}$ & $\begin{array}{l}1.85374 \\
1.86869 \\
1.78970\end{array}$ & $\begin{array}{c}\sigma: 0.7827 \mathrm{C} \text { sp } 0.87+0.6224 \text { Os sp } 1.65 \mathrm{~d} 1.99 \\
\pi: 0.5916 \mathrm{C} \text { sp50.04+0.8063 Os p99.99 d99.99 } \\
\pi: \quad 0.5071 \mathrm{C} \text { p } 1.00+0.8619 \text { Os p } 1.00 \mathrm{~d} 6.91\end{array}$ \\
\hline Me & $\begin{array}{l}1.85492 \\
1.87665 \\
1.79568\end{array}$ & $\begin{array}{c}0.7857 \text { C sp } 0.85+0.6186 \text { Os sp } 1.68 \mathrm{~d} 1.96 \\
0.5826 \text { C p } 84.98+0.8128 \text { Os p } 1.00 \mathrm{~d} 6.41 \\
0.5056 \text { C p } 1.00+0.8628 \text { Os p } 1.00 \mathrm{~d} 7.03\end{array}$ \\
\hline $\mathbf{N H}_{2}$ & $\begin{array}{l}1.85357 \\
1.87298\end{array}$ & $\begin{array}{c}0.7867 \mathrm{C} \text { sp } 0.85+0.6173 \text { Os sp } 1.65 \mathrm{~d} 1.92 \\
0.5926 \mathrm{C} \text { p } 74.86+0.8055 \text { Os p } 1.00 \mathrm{~d} 6.17\end{array}$ \\
\hline $\mathrm{OH}$ & $\begin{array}{l}1.85446 \\
1.87377\end{array}$ & $\begin{array}{c}0.7871 \text { C sp } 0.84+0.6168 \text { Os sp } 1.64 d 1.90 \\
0.5949 \text { C } \text { sp74.61 }+0.8038 \text { Os p } 1.00 \mathrm{~d} 6.18\end{array}$ \\
\hline $\mathbf{C N}$ & $\begin{array}{l}1.85468 \\
1.87453 \\
1.76818 \\
\end{array}$ & $\begin{array}{c}0.7847 \text { C sp } 0.85+0.6199 \text { Os sp } 1.66 \mathrm{~d} 1.95 \\
0.5854 \text { C p } 61.79+0.8107 \text { Os p99.99 d99.99 } \\
0.5233 \text { C p } 1.00+0.8521 \text { Os p } 1.00 d 6.74\end{array}$ \\
\hline CHO & $\begin{array}{l}1.85594 \\
1.88107 \\
1.75476\end{array}$ & $\begin{array}{c}0.7869 \text { C sp } 0.85+0.6171 \text { Os sp } 1.70 \mathrm{~d} 1.94 \\
0.5701 \text { C p86.44+0.8216 Os p99.99 d99.99 } \\
0.5230 \text { C p } 1.00+0.8523 \text { Os p } 1.00 d 6.73\end{array}$ \\
\hline $\mathrm{COOH}$ & $\begin{array}{l}1.85523 \\
1.87771 \\
1.76576\end{array}$ & $\begin{array}{c}0.7859 \text { C sp } 0.85+0.6184 \text { Os sp } 1.68 \mathrm{~d} 1.95 \\
0.5763 \text { C p } 75.59+0.8172 \text { Os p } 1.00 \text { d } 6.48 \\
0.5233 \text { C p } 1.00+0.8522 \text { Os p } 1.00 \text { d } 6.82\end{array}$ \\
\hline $\mathrm{NO}_{2}$ & $\begin{array}{l}1.85528 \\
1.87658 \\
1.76385\end{array}$ & $\begin{array}{c}0.7849 \text { C sp } 0.85+0.6197 \text { Os sp } 1.67 \mathrm{~d} 1.95 \\
0.5816 \text { C p } 62.76+0.8135 \text { Os p } 1.00 \mathrm{~d} 6.34 \\
0.5275 \text { C p } 1.00+0.8495 \text { Os p } 1.00 \mathrm{~d} 6.70\end{array}$ \\
\hline
\end{tabular}




\begin{tabular}{|c|c|c|}
\hline $\mathbf{X}$ & occupancy & NBO \\
\hline H & 1.83683 & $\sigma: 0.7705 \mathrm{C}$ sp $1.87+0.6375$ Os sp $2.06 \mathrm{~d} 2.60$ \\
\hline $\mathbf{F}$ & 1.83961 & $\sigma: 0.7731 \mathrm{C}$ sp $1.84+0.6343$ Os sp $2.12 \mathrm{~d} 2.64$ \\
\hline $\mathbf{C l}$ & 1.83808 & $\sigma: 0.7719$ C sp $1.84+0.6358$ Os sp $2.09 \mathrm{~d} 2.62$ \\
\hline $\mathrm{Br}$ & 1.83782 & $\sigma: 0.7715 \mathrm{C} \mathrm{sp} 1.85+0.6362 \mathrm{Os}$ sp $2.09 \mathrm{~d} 2.62$ \\
\hline Me & 1.83612 & $\sigma: 0.7707 \mathrm{C}$ sp $1.88+0.6372$ Os sp $2.08 \mathrm{~d} 2.62$ \\
\hline $\mathbf{N H}_{2}$ & 1.83575 & $\sigma: 0.7743 \mathrm{C}$ sp $1.86+0.6328$ Os sp $2.12 \mathrm{~d} 2.62$ \\
\hline $\mathbf{O H}$ & 1.83624 & $\sigma: 0.7725 \mathrm{C} \mathrm{sp} 1.87+0.6350$ Os sp $2.09 \mathrm{~d} 2.59$ \\
\hline $\mathbf{C N}$ & 1.83775 & б: $0.7714 \mathrm{C}$ sp $1.85+0.6363$ Os sp $2.04 \mathrm{~d} 2.58$ \\
\hline СНО & 1.83762 & $\sigma: 0.7718 \mathrm{C}$ sp $1.84+0.6359$ Os sp $2.02 \mathrm{~d} 2.56$ \\
\hline $\mathrm{COOH}$ & 1.83666 & $\sigma: 0.7700 \mathrm{C}$ sp $1.86+0.6381$ Os sp $2.03 \mathrm{~d} 2.57$ \\
\hline $\mathrm{NO}_{2}$ & 1.83866 & $\sigma: 0.7712$ C sp $1.83+0.6366$ Os sp $2.04 \mathrm{~d} 2.57$ \\
\hline
\end{tabular}

\section{CONCLUSION}

The molecular structures and properties of osmabenzyne and parasubstituted osmabenzynes were discussed in this paper on the basis of theoretical calculated geometrical parameters and atomic charges (NBO). We have been determined the parameters such as the $\eta$ (hardness), $\mu$ (chemical potential) and $\omega$ (electrophilicity index) by using HOMO and LUMO energy values for all compounds. Also, UV-vis spectra were investigated by using TD-DFT method. NICS $(1)_{z z}$ values shown more aromaticity for electron withdrawing substituents

\section{REFERENCES}

1. G. Jia, Acc. Chem. Res., 2004, 37, 479.

2. G. Jia, Coord. Chem. Rev. , 2007, 251, 2167.

3. J. Chen, H. H. Y. Sung, I. D. Williams, Z. Lin, G. Jia, Angew. Chem. Inter.l Ed., 2011, 50, 10675.

4. J. Chen, G.Jia, Coord. Chem. Rev., 2013, 257, 2491.

5. X-Y.Cao, Q. Zhao, Z. Lin, H. Xia, Acc. Chem. Res., 2014, 47, 341.

6. G. Jia, Organometallics 2013, 32, 6852.

7. G. P. Elliott, W. R. Roper, J. M. Waters, J. Chem. Soc., Chem. Commun., 1982, 1982, 811.

8. T. B. Wen, Z. Y. Zhou, G. Jia, Angew. Chem. Int. Ed., 2001, 40, 1951.

9. T. B. Wen, W. Y. Hung, H. H. Y. Sung, I. D. Williams, G. Jia, J. Am. Chem. Soc. , 2005, 127, 2856.

10. W. Y. Hung, J. Zhu, T. B. Wen, K. P. Yu, H. H. Y. Sung, I. D. Williams, Z. Lin, G. Jia, J. Am. Chem. Soc., 2006, 128, 13742.

11. T. B.Wen, S. M. Ng, W. Y. Hung, Z. Y. Zhou, M. F. Lo, L. Y. Shek, I D.Williams, Z. Lin, G. Jia, J. Am. Chem. Soc. , 2003, 125, 884.

12. G. He, J. Zhu, W. Y. Hung, T. B.Wen, H. H. Y. Sung, I. D. Williams, Z. Lin, G. Jia, Angew. Chem. Int. Ed. , 2007, 46, 9065.

13. S.-Y. Yang, X-Y. Li, Y.-Z. Huang, J.Organomet. Chem. , 2002, 658, 9.

14. M. J. Frisch, G. W. Trucks, H. B. Schlegel, G. E. Scuseria, M. A. Robb, J. R. Cheeseman, J. A. Montgomery, Jr., T. Vreven, K. N. Kudin, J. C. Burant, J. M. Millam, S. S. Iyengar, J. Tomasi, V. Barone, B. Mennucci, M. Cossi, G. Scalmani, N. Rega, G. A. Petersson, H. Nakatsuji, M. Hada, M. Ehara, K. Toyota, R. Fukuda, J. Hasegawa, M. Ishida, T. Nakajima, Y. Honda, O. Kitao, H. Nakai, M. Klene, X. Li, J. E. Knox, H. P. Hratchian, J. B. Cross, C. Adamo, J. Jaramillo, R. Gomperts, R. E. Stratmann, O. Yazyev, A. J. Austin, R. Cammi, C. Pomelli, J. W. Ochterski, P. Y. Ayala, K. Morokuma, G. A. Voth, P. Salvador, J. J. Dannenberg, V. G. Zakrzewski, S. Dapprich, A. D. Daniels, M. C. Strain, O. Farkas, D. K Malick, A. D. Rabuck, K. Raghavachari, J. B. Foresman, J. V. Ortiz, Q. Cui, A. G. Baboul, S. Clifford, J. Cioslowski, B. B. Stefanov, G. Liu, A Liashenko, P. Piskorz, I. Komaromi, R. L. Martin, D. J. Fox, T. Keith, M. A. Al-Laham, C. Y. Peng, A. Nanayakkara, M. Challacombe, P. M. W. Gill, B. Johnson, W. Chen, M. W. Wong, C. Gonzalez, J. A. Pople, Revision B.03 ed., Gaussian, Inc., Pittsburgh PA, 2003.
15. R. Ditchfield, W. J. Hehre, J. A. Pople, J. Chem. Phys. , 1971, 54, 724.

16. W. J. Hehre, R. Ditchfield, J. A. Pople, J. Chem. Phys., 1972, 56, 2257.

17. M. S. Gordon, Chem. Phys. Lett. , 1980, 76, 163.

18. J.-P. Blaudeau, M. P. McGrath, L. A. Curtiss, L. Radom, J. Chem. Phys. , 1997, 107, 5016 .

19. M. M. Francl, W. J. Pietro, W. J. Hehre, J. S. Binkley, D. J. DeFrees, J. A. Pople, M. S. Gordon, J. Chem. Phys. , 1982, 77, 3654.

20. V. A. Rassolov, J. A. Pople, M. A. Ratner, T. L. Windus, J. Chem. Phys. 1998, 109, 1223 .

21. V. A. Rassolov, M. A. Ratner, J. A. Pople, P. C. Redfern, L. A. Curtiss, J. Comp. Chem., 2001, 22, 976.

22. P. J. Hay, W. R. Wadt, J.Chem.Phys, 1985, 82, 299.

23. P. J. Hay, W. R. Wadt, J.Chem.Phys, 1985, 82, 284.

24. A. Schaefer, H. Horn, R. Ahlrichs, J.Chem.Phys, 1992, 97, 2571.

25. C. Adamo, V. Barone, J. Chem. Phys., 1998, 108, 664.

26. J. P. C. A. M. Porembski and J. C. Weisshaar, 4851 (2001). J. Phys. Chem. A 105, 4851 (2001). 2001, 105, 4851

27. M. Porembski, J. C. Weisshaar, J. Phys. Chem. A, 2001, 105, 6655.

28. Y. Zhang, Z. Guo, X.-Z. You, J. Am. Chem. Soc., 2001, 123, 9378.

29. R. C. Dunbar, J. Phys. Chem. A 2002, 106, 7328.

30. D. A. Keleiman, Phy. Rev., 1962, 126, 1977.

31. E. Runge, E. K. U. Gross, Phys. Rev. Lett. , 1984, 52, 997.

32. A. E. Reed, L. A. Curtiss, F. Weinhold, Chem. Rev. , 1988, 88, 899.

33. E. D. Glendening, A. E. Reed, J. E. Carpenter, F. Weinhold, 3.1. ed., Gaussian Inc, Pittsburg, PA, 2003.

34. N. M. O’Boyle, A. L. Tenderholt, K. M. Langner, J. Comp. Chem., 2008, 29,839 .

35. Z. Chen, C. S. Wannere, C. Corminboeuf, R. Puchta, P. v. R. Schleyer, Chem. Rev, 2005, 105, 3842.

36. P. v. R. Schleyer, C. Marker, A. Dransfeld, H. Jiao, N. J. R. V. Hommes, J. Am. Chem. Soc. , 1996, 118, 6317.

37. P. v. R. Schleyer, M.Monohar, Z. Wang, B. Kiran, H. Jiao, R. Puchta, N. J. R. V. Hommes, Org. Lett, 2001, 3, 2465.

38. C. Corminboeuf, T. Heine, G. Seifert, P. v. R. Schleyer, J. Weber, Phys. Chem. Chem. Phys, 2004, 6, 273.

39. H. Fallah-Bagher-Shaidaei, C. S. Wannere, C. Corminboeuf, R. Puchta, P. v. R. Schleyer, Org. Lett, 2006, 8, 863.

40. K. Wolinski, J. F. Hinton, P. Pulay, J. Am. Chem. Soc., 1990, 112, 8251

41. H. Cheng, J. Feng, A. Ren, J. Liu, Acta Chim. Sin., 2002, 60, 830.

42. Y. Sun, X. Chen, L. Sun, X. Guo, W. Lu, Chem. Phys. Lett., 2003, 381. 